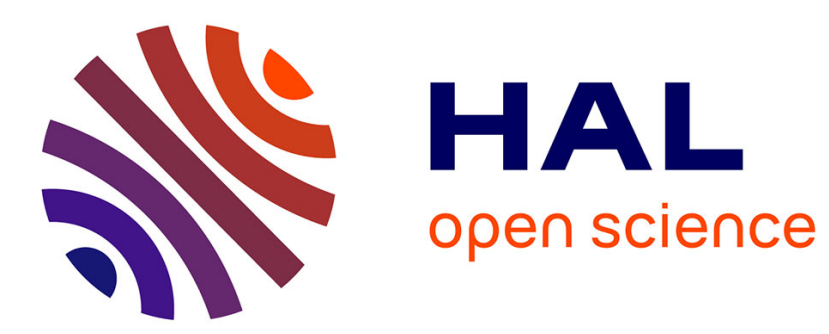

\title{
Water quantification in olivine and wadsleyite by Raman 2spectroscopy and study of errors and uncertainties
}

\author{
Loïs Martinek, Nathalie Bolfan-Casanova
}

\section{To cite this version:}

Loïs Martinek, Nathalie Bolfan-Casanova. Water quantification in olivine and wadsleyite by Raman 2spectroscopy and study of errors and uncertainties. American Mineralogist, 2020, 10.2138/am-20217264. hal-02996319

\author{
HAL Id: hal-02996319 \\ https://hal.uca.fr/hal-02996319
}

Submitted on 9 Nov 2020

HAL is a multi-disciplinary open access archive for the deposit and dissemination of scientific research documents, whether they are published or not. The documents may come from teaching and research institutions in France or abroad, or from public or private research centers.
L'archive ouverte pluridisciplinaire HAL, est destinée au dépôt et à la diffusion de documents scientifiques de niveau recherche, publiés ou non, émanant des établissements d'enseignement et de recherche français ou étrangers, des laboratoires publics ou privés. 


\section{3 spectroscopy and study of errors and uncertainties}

\author{
MARTineK Lö̈s ${ }^{1}$ AND Bolfan-CASANova NathaLie ${ }^{1}$
}

${ }^{1}$ Laboratoire Magmas et Volcans, 6 avenue Blaise Pascal, TSA 60026 - CS 60026, 63178 Aubière Cedex

\section{Abstract}

The study of nominally anhydrous minerals with vibrational spectroscopy, despite its sensitivity, tends to produce large uncertainties (in absorbance or intensity) if the observed dispersion of the values arising from the anisotropy of interaction with light in non-cubic minerals is not assessed. In this study, we focused on Raman spectroscopy, which allows the measurement of crystals down to few micrometers in size in back-scattered geometry, and with any water content, down to 200 ppm by weight of water. Using synthetic hydrous single-crystals of olivine and wadsleyite, we demonstrate that under ideal conditions of measurement and sampling, the data dispersion reaches $\pm 30 \%$ of the average (at $1 \sigma$ ) for olivine, and $\pm 32 \%$ for wadsleyite, mostly because of their natural anisotropy. As this anisotropy is linked to physical properties of the mineral, it should not be completely considered as error without treatment. By simulating a large number of measurements with a 3D model of the $\mathrm{OH} / \mathrm{Si}$ spectral intensity ratio for olivine and wadsleyite as a function of orientation, we observe that although dispersion increases when increasing the number of measured points in the sample, analytical error decreases, and the contribution of anisotropy to this error decreases. With a sufficient number of 
21 points (five to ten, depending on the measurement method), the greatest contribution to the error

22 on the measured intensities is related to the instrument's biases, and reaches 12 to $15 \%$ in ideal

23 cases, indicating that laser and power drift corrections have to be carefully performed. We finally

24 applied this knowledge on error sources (to translate data dispersion into analytical error) on

25 olivine and wadsleyite standards with known water contents to build calibration lines for each

26 mineral in order to convert the intensity ratio of the water bands over the structural bands $(\mathrm{OH} / \mathrm{Si})$

27 to water content. The conversion factor from $\mathrm{OH} / \mathrm{Si}$ to ppm by weight of water $\left(\mathrm{H}_{2} \mathrm{O}\right)$ is

$2893108 \pm 24005$ for olivine, $250868 \pm 45591$ for iron-bearing wadsleyite, and $57546 \pm 13916$ for iron-

29 free wadsleyite, showing the strong effect of iron on the spectral intensities.

Keywords: wadsleyite, olivine, nominally anhydrous minerals, Raman spectroscopy,

31 water quantification

\section{INTRODUCTION}

Even though the major mineral phases of the Earth's mantle are nominally anhydrous,

34 many of them are known to contain water as $\mathrm{OH}$ point defects in their structure (Bell and

35 Rossman, 1992; Smyth and Keppler, 2006; Peslier 2010; Demouchy \& Bolfan-Casanova, 2016).

36 The water storage capacity of the most abundant upper mantle mineral, namely olivine, has been

37 the subject of many studies, however most reports concern simple systems or single crystal

38 olivine (e.g. Kohlstedt et al. 1996; Withers \& Hirschmann 2007 and 2008; Bali et al. 2008;

39 Kovács et al. 2010; Férot \& Bolfan-Casanova 2012; Litasov et al. 2014, Yang et al. 2016).

40 Single-phase experiments allow the growth of single crystals large enough to be suitable for any

41 analytical method, especially absorption infrared spectroscopy using Fourier transform infrared

42 (FTIR), secondary ion mass spectrometry (SIMS), or elastic recoil detection analysis (ERDA). 
In experiments with natural mantle compositions on the other hand, olivine,

44 orthopyroxene, clinopyroxene and garnet can coexist, strongly limiting crystal growth. These

45 samples often display crystal sizes from 20 to $50 \mu \mathrm{m}$, limiting the use of the conventional

46 methods cited above on the fine-grained samples. Investigation of the storage capacity in more

47 complex systems such as peridotite has been carried out and the small grain size of the grains

48 required the use of SIMS (few tens of cubic micrometers analyzed) or even nano-SIMS (one or

49 two order of magnitude less) ( see Ardia et al., 2012; Tenner et al., 2012; Novella et al., 2014).

50 This technique is complicated to use because of high background levels of $\mathrm{H}$, complex

51 preparation to avoid $\mathrm{H}$ contamination and the need for well-characterized standards (Koga et al.

52 2003, Mosenfelder et al. 2011).

FTIR is frequently used sensitive technique to quantify hydroxyl content in nominally

54 anhydrous minerals, which also gives structural information about $\mathrm{H}$ point defects. Reliable

55 methods exist to quantify water in anisotropic minerals using FTIR, and a consequent literature

56 exists on the subject (e.g., Libowitzsky and Rossman 1996; Asimow et al. 2006; Kovács et al.

57 2008; Withers et al. 2012, Withers 2013; Qiu et al. 2018). However, in the case of very water-

58 rich samples as, for example, wadsleyite, a high-pressure polymorph of olivine, that can contain

59 up to 3.2 weight percent of water (Inoue et al., 1995), infrared spectroscopy requires an important

60 thinning of the samples (which may cause their loss) in order to avoid the entire absorption of the

61 infrared signal.

In this study, we used confocal polarized Raman spectroscopy (the laser source being

63 polarized, the incident beam is therefore also polarized). This technique offers several advantages

64 for water quantification in synthetic minerals with a small grain size and low to very high water

65 contents. Regarding sample preparation, $\mathrm{OH}$ quantification using back-scattered Raman 
spectroscopy requires only one side of the sample to be polished, while double polishing is required in the measurement of absorbance using FTIR. Unfortunately, very thin polishing of the sample can irremediably damage them, especially those sintered under conditions where fluids are highly wetting, which is the case of the conditions of the deep upper mantle (Yoshino et al. 2007). The detection limit of water quantification using Raman spectroscopy (around 50-100 ppm wt) may be a problem with samples synthesized under conditions of the uppermost mantle, where the water solubility is the lowest for many mineral species (Férot \& BolfanCasanova 2012, Yang 2016), but any higher concentration can be measured (Bolfan-Casanova et fine-grained samples (down to crystal sizes around $5 \mu \mathrm{m}$ ) without difficulties. The time required for reasonably precise measurements (some minutes) is low enough to multiply the number of measured points on different crystals throughout the sample and have a statistically correct coverage of the whole sample. One major drawback of Raman spectroscopy is that the intensity absorption depends on many factors in addition to the concentration, such as the intensity of the incident laser, confocality and lens magnification, which control the volume of sample that is

81 excited by the laser beam. Moreover, the chosen gratings and the optics of the spectrometer 82 (instrument-dependent parameters), as well as the optical properties of the sample or its surface 83 state will affect the efficiency of the measurement (see e.g. Mercier et al. 2009, Schiavi et al. 2018; Zarei et al. 2018). In contrast, the absorbance measured using FTIR depends solely on the

85 thickness, concentration and absorptivity of the sample itself, following a relationship known as

86 the Beer-Lambert law. In addition, in absorbance spectroscopy the intensity transmitted by the 87 sample is always normalized to that of the incident beam, which tends to eliminate instrumental 88 biases on the intensity of the signal from the sample. 
This is the peer-reviewed, final accepted version for American Mineralogist, published by the Mineralogical Society of America. The published version is subject to change. Cite as Authors (Year) Title. American Mineralogist, in press.

DOI: https://doi.org/10.2138/am-2021-7264. http://www.minsocam.org/

Raman spectroscopy is widely used to quantify $\mathrm{H}_{2} \mathrm{O}$ concentrations in glasses or melt

90 inclusions (e.g., Thomas et al. 2008; Mercier et al. 2009; Schiavi et al., 2018). In these studies,

91 quantification of the water concentration relies on the comparison of the $\mathrm{OH} / \mathrm{Si}$ of the unknown

92 to that of well-characterized standards measured under identical conditions, as the $\mathrm{OH}$ intensity

93 has been shown to increase linearly with water content. Here, $\mathrm{OH} / \mathrm{Si}$ is defined by the integrated

94 intensity of the water band normalized to that of the silicate vibrations (see the following section

95 for details). As numerous factors may affect the measurement efficiency (such as variation of

96 focusing depth or surface quality), using the ratio of the $\mathrm{OH}$ band area over that of silica bands

97 area reduces the data dispersion or scatter, as both regions are equally affected by focusing or

98 surface variations. Calibrations of the method have been proposed by Thomas et al. (2008 and

99 2015) for garnet, Bolfan-Casanova et al. (2014) for olivine, Thomas et al. (2015) for ringwoodite,

100 and Weis et al. (2018) for orthopyroxene (this last study having used also forward-scattering).

101

Previous water content quantification in olivine conducted with Raman spectroscopy

102 often display large error bars on their results (Bolfan-Casanova et al. 2014). In this study, we

103 demonstrate that those error bars are significantly related to the dispersion (used in the statistical

104 meaning of the term throughout this work) of the relative intensities of the different vibrational

105 modes caused by the anisotropy of the minerals. As this anisotropy is a natural consequence of

106 the structure and symmetry of the crystal, it is not directly related to error, and can even be used

107 to get information on orientation (see for example Ishibashi et al. 2008). Firstly, we studied the

108 relative effect of the different error sources and of anisotropy on the statistical dispersion of

109 measurements in hydrated olivine and wadsleyite single crystals and used it to propose a method

110 to estimate the analytical error from the data dispersion of the measurements using polarized 
This is the peer-reviewed, final accepted version for American Mineralogist, published by the Mineralogical Society of America. The published version is subject to change. Cite as Authors (Year) Title. American Mineralogist, in press.

DOI: https://doi.org/10.2138/am-2021-7264. http://www.minsocam.org/

111 unanalyzed Raman spectroscopy. We then propose a calibration for water quantification in

112 olivine and wadsleyite based on standards characterized by FTIR or ERDA methods.

\section{METHODS}

\section{Synthesis of olivine and wadsleyite}

115 Olivine and wadsleyite single crystals were synthesized in the multi-anvil press at 12 and

$11615 \mathrm{GPa}$ and at 1200 and $1350^{\circ} \mathrm{C}$ from San Carlos olivine as starting material. Olivine single

117 crystals and powder were placed in a folded rhenium foil capsule, placed itself in a welded gold-

118 palladium capsule containing brucite powder. The experimental assembly consisted of an $\mathrm{MgO}$

119 octahedron containing $\mathrm{Cr}_{2} \mathrm{O}_{3}$, a zirconia thermal insulator, a $\mathrm{LaCrO}_{3}$ heater with molybdenum

120 electrodes in contact with the anvils and an $\mathrm{MgO}$ central part containing the capsule. Temperature

121 was controlled using a W-Re thermocouple (5\% and 26\% Re). Experiments were conducted at

122 the Laboratoire Magmas et Volcans (LMV, Clermont-Ferrand, France) on a Voggenreiter Mavo-

123 press LP 1500 tons multi-anvil press equipped with a Kawai-Endo apparatus. Heating was

124 performed and controlled by a Pacific 140-AMX AC power source. Secondary anvils were 32

$125 \mathrm{~mm}$ tungsten carbide cubes with 8 and $6 \mathrm{~mm}$ truncations. Olivine synthesis duration was 4.5

126 hours at $1200{ }^{\circ} \mathrm{C}$, and wadsleyite synthesis lasted 2 hours at $1350{ }^{\circ} \mathrm{C}$. For both syntheses,

127 temperature was gradually decreased after the experiment (around $50{ }^{\circ} \mathrm{C}$ per minute) instead of

128 quenching to prevent crystal fracturation. Recovered crystals were oriented using polarized light

129 microscopy for olivine and X-ray diffraction for wadsleyite, and then cut and mirror polished

130 perpendicular to crystallographic axes (see Figure 1). Olivine and wadsleyite are both

131 orthorhombic so display an anisotropic behavior with respect to light absorption. Wadsleyite has

132 been reported to become monoclinic above $0.5 \mathrm{wt} \% \mathrm{H}_{2} \mathrm{O}$ using X-ray diffraction (Jacobsen et al. 
133 2005), however we did not detect any noticeable spectral difference that could be due to this

134 small change in the $\beta$-angle.

\section{FTIR spectroscopy}

Most of the samples used in order to calibrate the Raman quantification method were

137 olivines characterized using FTIR by Férot \& Bolfan-Casanova (2012). These water content

138 values were updated using the most recent calibration of the infrared extinction coefficient $(\varepsilon)$

139 determined using ERDA by Withers et al. (2012) of $452001 \mathrm{~mol}_{\mathrm{H}_{2} \mathrm{O}}^{-1} \mathrm{~cm}^{-2}$ instead of the 284501

$140 \mathrm{~mol}_{\mathrm{H}_{2} \mathrm{O}}^{-1} \mathrm{~cm}^{-2}$ value given by Bell et al. (2003). This decreases all the water contents of olivine

141 reported in Férot and Bolfan-Casanova (2012) by a factor of 1.589.

Polarized spectra acquired for this study were collected on a Vertex70 Brucker

143 spectrometer coupled to a Hyperion microscope with a $15 \times$ lens, condenser and knife-edge

144 apertures creating a rectangular target area of $40-50 \mu \mathrm{m}$. Samples were analyzed on a $\mathrm{CaF}_{2} \mathrm{plate}$

145 at a resolution of $2 \mathrm{~cm}^{-1}$, with 200 to 300 accumulations. After background subtraction and

146 atmospheric correction, a cubic baseline correction has been applied on the 1500 to $4000 \mathrm{~cm}^{-1}$

147 area, and integration calculated in the 2700 to $3720 \mathrm{~cm}^{-1}$ area. The absorbance is then used to

148 calculate the $\mathrm{H}_{2} \mathrm{O}$ content based on Beer Lambert's law (see equation 1) with the integrated molar

149 absorption coefficient (also called extinction coefficient) cited above, and a density factor $X$ of

$15055211 \cdot \mathrm{mol}_{\mathrm{H} 2 \mathrm{O}}{ }^{-1}$ (used to convert $\operatorname{mol}_{\mathrm{H} 2 \mathrm{O}} \cdot \mathrm{l}^{-1}$ to $\mathrm{ppm}$ by weight of $\mathrm{H}_{2} \mathrm{O}$, equal to $18.02 \times 10^{6} / \rho$ ). The

151 density $\rho$ has been calculated from Fischer \& Medaris (1969) accounting for the olivine

152 composition. The equation used is the following, with $\varepsilon$ being the infrared extinction coefficient,

$153 A_{\text {tot }}$ the total absorbance, and $d$ the thickness of the sample in centimeters: 
Equation 1

$$
C_{H_{2} O}=X \times \frac{A_{t o t}}{\varepsilon \times d}
$$

155

\section{Raman spectroscopy}

Raman spectra were collected at LMV using an InVia confocal Raman microspectrometer manufactured by Renishaw and equipped with a $532 \mathrm{~nm}$ diode laser $(200 \mathrm{~mW}$ output power), a Peltier-cooled CCD detector of $1024 \times 256$ pixels, a motorized XYZ stage and a Leica DM 2500M optical microscope. Scattered light was collected in a back-scattered geometry. An edge filter effectively reduced both Rayleigh scattered photons and photons from the exciting laser source at $0 \mathrm{~cm}^{-1}$ that had been reflected by the sample surface. A 2400 grooves $/ \mathrm{mm}$ grating was used for the analyses, which resulted in a spectral resolution between $1.3 \mathrm{~cm}^{-1}$ (around 100 $\mathrm{cm}^{-1}$ ) and $0.72 \mathrm{~cm}^{-1}$ (around $3700 \mathrm{~cm}^{-1}$ ). All spectra were acquired with polarized light without analyzer, and sample was rotated under the beam to change the polarization angle. $\mathrm{A} \times 100$ microscope lens (numerical aperture 0.9) was used and the slit aperture was set to $20 \mu \mathrm{m}$ (high confocality setting). Daily calibration of the spectrometer was performed based on a Si 520.5 $\mathrm{cm}^{-1}$ peak. The effective laser power (changed by filters) used was 65 to $71 \mathrm{~mW}$ for olivine, and 8 to $9 \mathrm{~mW}$ for wadsleyite and glass (low enough power to prevent destabilization and dehydration) and was measured to normalize spectra to $1 \mathrm{~mW}$. A power of 125 to $140 \mathrm{~mW}$ can cause some damages on water-rich olivine, and a power of $15 \mathrm{~mW}$ caused a slight $\mathrm{OH}$ intensity reduction in wadsleyite with very high water content (sample $2054,3.4 \%$ in weight), but no dehydration or destabilization effect has been observed with the lower laser power values finally chosen. A hydrous basaltic glass (see Schiavi et al. 2018) is used to check and be able to correct for power drifts and efficiency drifts along the different area of measurement. 
As already stated above, the quantification of water concentration is based on the

176 measurement of the $\mathrm{OH}$ band integrated intensity normalized to the silicate band integrated

177 intensity. Under static conditions of measurement, the window analyzed using a grating of 2400

178 groves $/ \mathrm{mm}$ decreases from approximately $1200 \mathrm{~cm}^{-1}$ at low wavenumbers to $800 \mathrm{~cm}^{-1}$ at high

179 wavenumbers. For all samples and standards, Si area refers to wavenumbers from 61 to 1318

$180 \mathrm{~cm}^{-1}$ centered on $720 \mathrm{~cm}^{-1}$, and $\mathrm{OH}$ area refers to wavenumbers from 2978 to $3784 \mathrm{~cm}^{-1}$ centered

181 on $3400 \mathrm{~cm}^{-1}$. Both areas were chosen to contain all the needed peaks and bands. Acquisition

182 times are short for the Si area because of its high intensity, to prevent saturation of the CCD

183 detector, and longer for the $\mathrm{OH}$ area to increase the signal to noise ratio, the $\mathrm{OH}$ bands being

184 much weaker. Thus, acquisition times were $2 \times 5 \mathrm{~s}$ for the $\mathrm{Si}$ area, and $5 \times 60 \mathrm{~s}$ for the $\mathrm{OH}$ area of

185 olivine and wadsleyite. For the glass, the acquisition times were $4 \times 10 \mathrm{~s}$ for the $\mathrm{Si}$ area, and

$1865 \times 120 \mathrm{~s}$ for the $\mathrm{OH}$ area. The daily variations of the spectrometer were corrected by normalizing

187 to the average $\mathrm{OH} / \mathrm{Si}$ intensity ratio of the hydrated glass measured in each measurement session,

188 each of those consisting on two random points on the glass sample, providing a more

189 reproducible $\mathrm{OH} / \mathrm{Si}$ intensity ratio here called $(\mathrm{OH} / \mathrm{Si})_{\text {Smp_Norm. The normalization operation is }}$

190 shown in equation 2 , where $(\mathrm{OH} / \mathrm{Si})_{\mathrm{Smp} \text { Meas }}$ is the average $\mathrm{OH} / \mathrm{Si}$ of the measured sample,

$191(\mathrm{OH} / \mathrm{Si})_{\text {Glass_Meas }}$ is the standard glass $\mathrm{OH} / \mathrm{Si}$ measured in the same session as the sample, and

$192(\mathrm{OH} / \mathrm{Si})_{\text {Glass_Std }}$ is the measurement of the $\mathrm{OH} / \mathrm{Si}$ of the glass measured in the same session as the

193 standards. The result is the normalized $\mathrm{OH} / \mathrm{Si}$ of the sample $(\mathrm{OH} / \mathrm{Si})_{\text {Smp_Norm. }}$

\section{Equation 2}

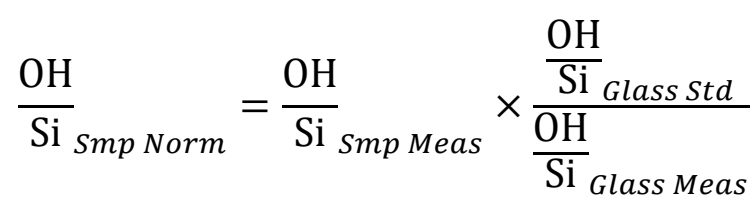


This is the peer-reviewed, final accepted version for American Mineralogist, published by the Mineralogical Society of America. The published version is subject to change. Cite as Authors (Year) Title. American Mineralogist, in press. DOI: https://doi.org/10.2138/am-2021-7264. http://www.minsocam.org/

The procedure of baseline correction is essential in obtaining reproducible values of

$196 \mathrm{OH} / \mathrm{Si}$ for each phase (see Figure 2 and supplementary materials 1 ). The baseline shape is linear

197 for the olivine Si area (rarely cubic), cubic for its $\mathrm{OH}$ area, cubic or polygonal for the wadsleyite

$198 \mathrm{Si}$ area and cubic for its $\mathrm{OH}$ area. The anchor points used to define the baseline are shown in

199 Figure 2. The spectra used afterwards for integrations are the raw spectra subtracted of the

200 baseline, and divided by the total acquisition time and the laser power, to normalize each

201 spectrum to a power of $1 \mathrm{~mW}$ and an acquisition time of $1 \mathrm{~s}$. It has to be noted that this is not the

202 unit of the spectra, as the intensity measured on each spectrum depends on various parameters of

203 the instrument such as the grating and the wave number, but can be labelled as counts $\cdot \mathrm{s}^{-1} \cdot \mathrm{mW}^{-1}$.

204 Integration consists in the area under the curve of the baseline-corrected and normalized

205 spectrum: [200, 1100] for the Si area and [3050, 3700] for the $\mathrm{OH}$ area of olivine, and [300,

206 1100] for the Si area and [3150,3700] for the $\mathrm{OH}$ area of wadsleyite (see Figure 2). The result of

207 this integration defines thereafter the intensity of the spectra. In the case of wadsleyite, iron-

208 bearing samples display a very intense band at $171 \mathrm{~cm}^{-1}$ that merges with the white line (at low

209 wavenumbers) rendering its baseline correction unreliable due to the difficult anchoring of the

210 baseline at low wavenumbers (see supplementary materials 1 ). This is why the integration of the

211 Si area of wadsleyite starts at a higher wavenumber of $300 \mathrm{~cm}^{-1}$.

212 For all the spectra of glass, the single-crystal spectra and some of the wadsleyite and

213 olivine samples, one measurement point consists in the $\mathrm{OH}$ intensity divided by the Si intensity

$214(\mathrm{OH} / \mathrm{Si}$ ratio $)$ with the same polarization angle, and is referred as "single points". On most of the

215 olivine and wadsleyite samples, one measurement point will be the average of two $\mathrm{OH} / \mathrm{Si}$ ratio

216 obtained from two measurements on the same crystal with orthogonal polarization angles, and is

217 referred as "orthogonal couples". 
219 to compare the different samples. Eight olivine and seven wadsleyite standard samples of various

220 known water contents have been used to build the calibration lines allowing the conversion from

$221 \mathrm{OH} / \mathrm{Si}$ ratio to water content. Water contents of olivine standards have been determined by FTIR, 222 using Withers et al. (2012) extinction coefficient, and those of wadsleyite standards were 223 measured by ERDA (Bolfan-Casanova et al. 2018).

\section{RESULTS}

\section{Quantification of the $\mathbf{O H} / \mathrm{Si}$ variation related to mineral orientation}

In order to assess the effect of orientation alone on the dispersion of the average $\mathrm{OH} / \mathrm{Si}$ value of each phase, polarized Raman spectra have been acquired on each face of the prepared

228 single crystals of olivine and wadsleyite. We acquired 19 spectra, from 0 to $180^{\circ}$, on each face

229 for both $\mathrm{OH}$ and $\mathrm{Si}$ area, and values for 190 to $350^{\circ}$ were calculated by symmetry. Normalized

$230 \mathrm{OH} / \mathrm{Si}$ values were then fitted using equation 3 for olivine and equation 4 for wadsleyite (see

231 Figure 3).

232 Equation 3

$$
\frac{\mathrm{OH}}{\mathrm{Si}}(\theta)=H+a_{1} \times \cos ^{2}\left(\theta+d_{1}\right)
$$

\section{Equation 4}

$$
\frac{\mathrm{OH}}{\mathrm{Si}}(\theta)=H+a_{1} \times \cos ^{2}\left(\theta+d_{1}\right)+a_{2} \times \cos ^{2}\left(2 *\left(\theta+d_{2}\right)\right)
$$

Here, $H$ is a constant depicting the minimum value for a given face adjusting the vertical

235 position of the curve; $a_{1}$ is the amplitude (the difference between the maximum and minimum 
This is the peer-reviewed, final accepted version for American Mineralogist, published by the Mineralogical Society of America. The published version is subject to change. Cite as Authors (Year) Title. American Mineralogist, in press.

DOI: https://doi.org/10.2138/am-2021-7264. http://www.minsocam.org/

236 intensities of the given face for equation 3) of the cosine describing the features with a period of

$237180^{\circ}$ (2-fold symmetry) shifted of an angle $d_{1} ; a_{2}$ is the amplitude of the cosine describing the

238 features with a period of $90^{\circ}$ (4-fold symmetry) shifted of an angle $d_{2}$. Each parameter has been

239 optimized to minimize the differences between the measurement data and the fitted curve. It has

240 to be noted that the necessity for introducing parameters $d$ arise from the fact that crystals are not

241 exactly polished following the crystallographic axes. These fits are thus empirical and only serve

242 the purpose of creating a model of the analyzed crystals. For olivine, this misalignment is around

$24310^{\circ}$ (as visible in Figure 3), and has later been neglected (the maxima of the faces (100) and (010)

244 have been aligned along crystallographic axes in the 3D model). On the other hand, the

245 misalignment of wadsleyite is high, and orientation has been lost, rendering necessary the use of

246 the shift parameters $d$. The observed component with a $90^{\circ}$ period is necessary in the case of

247 wadsleyite to fit correctly the measured intensity, and can mostly be noticed in the fits of the

248 intensity variations on the faces arbitrarily called F1, F2 and F3 (see M F1 and M F2 fit curves

249 around 150 and $330^{\circ}$ ).

Considering that the single-crystal analyzed is homogeneous in water content, the only

251 source of deviation between the modeled curve and the measured data is the combination of data

252 treatment error and measurement error. Data treatment error has been estimated from the

253 differences between repeated baseline correction and treatments of Raman spectra, and will be

254 referred as $E_{T r}$ in following equations, tables and figures. The estimated values for $E_{T r}$ on $\mathrm{OH} / \mathrm{Si}$

255 are $3.6 \%$ for olivine and $4.0 \%$ for wadsleyite. This error tends to remain small when the signal to

256 noise ratio is high enough. The second error source taken into account is the one caused by all

257 measurement uncertainties, such as surface irregularities or focus offset, and will be referred as

$258 E_{\text {Meas }}$. Supposing that $E_{\text {Meas }}$ and $E_{T r}$ are independent sources of error, the deviation of 
measurement points from the model is the square root of the sum of the two error sources

260 squared, and is provided by the fit shown in Figure 3. From this calculation, we obtain a

261 measurement related uncertainty $E_{\text {Meas }}$ reaching $4.4 \%$ for olivine, and $4.1 \%$ for wadsleyite. The

262 last source of error arises from the daily variation of the spectrometer efficiency and the method

263 used to correct it. Hence, the treatment and measurement errors related to this correction are the

264 cause of an additional error of $11.9 \%$, and will be referred as $E_{C o r}$. This value has been estimated

265 accounting for the measurement and data treatment errors related to the standard glass

266 measurement. The first two error, $E_{\text {Meas }}$ and $E_{T r}$, sources apply on each point separately, while the

267 correction error $E_{C o r}$ applies to all the points of a measurement session. The values of the 268 estimated errors are reported in table 1.

The intensity versus angle model curves (as shown in Figure 3) were then used to build a

$2703 \mathrm{D}$ model of $\mathrm{OH} / \mathrm{Si}$ variation as a function of crystallographic orientation. In Figure 3 it is visible

271 that the fitted curves do not coincide with the corresponding minima and maxima from the other

272 faces (for example, the maxima of the "a" and "b" curves for olivine are different, but both

273 describe the $\mathrm{OH} / \mathrm{Si}$ intensity parallel to the "c" axis and should be equal). These differences are

274 very likely to be caused by misalignment of the polished faces with respect to the

275 crystallographic axes. To obtain a continuous set of three curves in 3D (as depicted by the bold

276 lines in Figure 4), the amplitudes of the curves have been increased or decreased so that they

277 cross each other along the crystallographic axes, keeping at the same time the average value of

278 each curve constant. Intermediate orientation values were completed by combining those 279 acquired along crystallographic axes, each point of any orientation being obtained with equation $280 \quad 5:$ 


$$
\left(\frac{O H}{S i}\right)_{\alpha}=\sum\left(\frac{O H}{S i}\right)_{i} \times \cos ^{2}\left(\alpha_{i}\right)
$$

In this equation, any orientation $\alpha$ is defined by a vector with a norm equal to the corresponding $(\mathrm{OH} / \mathrm{Si})_{\alpha}$ value. This vector has one projection on each of the "a", "b" and "c"

284 planes corresponding to values $(\mathrm{OH} / \mathrm{Si})_{i}$ fitted with equation 3 or 4 for a given angle (see Figure

285 3). $(\mathrm{OH} / \mathrm{Si})_{\alpha}$ is then calculated as being the sum of these three $(\mathrm{OH} / \mathrm{Si})_{\mathrm{i}}$, each multiplied by the

286 squared cosine of the angle between the defined vector and its projection on the corresponding

287 plane. This operation results in a peanut-shaped three-dimensional $\mathrm{OH} / \mathrm{Si}$ model for each phase

288 when displayed in a 3D polar graph (see Figure 4, depicting $\mathrm{OH} / \mathrm{Si}$ variation in olivine and

289 supplementary materials 2 for wadsleyite). The $\mathrm{OH} / \mathrm{Si}$ is depicted here as the distance between

290 the peanut-shaped surface and the intersection of the a, b, and c axes. In both olivine and

291 wadsleyite cases, it can be observed that high $\mathrm{OH} / \mathrm{Si}$ values are located along one axis, identified

292 as the c-axis for olivine, and that variations seem approximately axisymmetric for both of them.

293 This modelling process can be applied to other orthorhombic minerals (or quadratic), each model

294 being based on its own measured $\mathrm{OH} / \mathrm{Si}$ values (as shown in Figure 3). Minerals with other 295 crystal system could still be modelled, but they might require a different procedure of polishing, 296 measurement and 3D model extrapolation.

\section{Distinguishing OH/Si natural dispersion and errors}

The 3D OH/Si distribution models for olivine and wadsleyite have then been used as basis

299 to simulate measurements, in order to untangle the effects of natural dispersion (i.e. due to 300 crystallographic orientation) and analytical uncertainties on the final error for any type of 301 measurement (single points or orthogonal couples) and as a function of the number of 
measurement points. To achieve this, the first step is to generate a set of random uniformly

303 distributed crystal orientations that simulates a polycrystalline sample. A random "longitude"

304 angle between 0 and $360^{\circ}$ is first generated (uniform distribution), and a second "latitude" angle

305 is generated with a semicircle distribution with a maximal probability for $0^{\circ}$ and a probability of

306 reaching zero when approaching 90 or $-90^{\circ}$. To each orientation corresponds an $\mathrm{OH} / \mathrm{Si}$ value

307 determined as described for the construction of the 3D model. On each point chosen among those

308 of this surface, the estimated measurement and treatment errors are applied, using equation 6.

309 Here, $X_{\text {Meas }}$ and $X_{T r}$ represent normally distributed random values with an average of zero, and a

310 standard deviation equal to the desired error component $E_{\text {Meas }}$ or $E_{T r}$. Each "modeled", or

311 simulated point $(\mathrm{OH} / \mathrm{Si})_{\mathrm{M}}$ has its own $X_{\text {Meas }}$ and $X_{T r}$ values, because those errors do apply on

312 every point separately and independently, finally yielding the "real" value $(\mathrm{OH} / \mathrm{Si})_{\mathrm{R}}$.

\section{Equation 6}

$$
\frac{\mathrm{OH}}{\mathrm{Si}}_{R}=\frac{\mathrm{OH}}{\mathrm{Si}_{M}} \times\left(1+X_{\text {Meas }}\right) \times\left(1+X_{T r}\right)
$$

For single point measurements, the simulated sample value will be the average of all the

$315(\mathrm{OH} / \mathrm{Si})_{\mathrm{R}}$, multiplied in the same way by $1+X_{\text {Cor }}$ to simulate the errors arising from the laser

316 power drift correction. In the case of orthogonal couples measurements, the two resulting

$317(\mathrm{OH} / \mathrm{Si})_{\mathrm{R}}$ values of each measurement point are averaged, then all points are again averaged

318 before applying the $1+X_{\text {Cor }}$ factor.

All the error and dispersion values used in the following section are expressed as relative

320 errors, in percent of deviation from the average. Hereafter, the goal is to get the standard

321 deviation and the average of each simulated measurement session for any number of 322 measurement points and repeat the operation a large number of times to get a result as 
323 statistically significant as possible. In this study, final values have been obtained for sets of 2 to

32430 points in both single point and orthogonal couples, with one million draws for each case. For

325 each number of points, the average of all the standard deviations of all sets of values has been

326 interpreted as the expected measured dispersion $D_{T h}$, and the standard deviation of all the

327 averages of all the set of points has been interpreted as the error expected for the measurement

$328\left(E_{T h}\right)$. Both $D_{T h}$ and $E_{T h}$ depend on the number of measurement points and on the technique used

329 for the measurement (single point or orthogonal couples). Dispersion increases when adding

330 points, reaching an approximate plateau past 10 points, and error decreases when adding points,

331 but stabilizes much slower past 30 points, limited by the contribution of $\mathrm{E}_{\mathrm{Cor}}$ to the final error 332 (see Figure 5).

The dispersion and error values obtained by the above simulation were then fitted to

334 obtain error propagation equations as a function of the number of points, the measurement

335 method, and the different errors sources. The natural dispersion caused by anisotropy can be

336 estimated from equation 7 below. Here $D_{N a t}$ is the natural dispersion, which is the expected

337 relative standard deviation obtained on a random set of measurements without any kind of error

338 added as a function of the number of points $(N) . D_{A n}$ represents the total anisotropy, and is the

339 same standard deviation as $D_{\text {Nat }}$, but for an infinite set of points, and finally " $a$ " is a fitting

340 parameter (all the values of the different parameters are shown in Table 1).

\section{$341 \quad$ Equation 7}

$$
D_{N a t}=D_{A n}-\frac{a}{N-1}
$$

342 Equations 8 and 9 also express the dispersion of values and in addition takes into account

343 the errors arising from measurement and data treatment. As the normalization related errors $\left(\mathrm{E}_{\mathrm{Cor}}\right)$ 
344 apply on all the points in the same way, it does not have any effect on the relative dispersion.

345 Equation 8 gives the expected dispersion for single points measurements, and equation 9 for

346 orthogonal couples. Here, $D_{A n}, " a "$ and $N$ are the same as in equation $7, E_{\text {Meas }}$ is the measurement

347 error, and $E_{T r}$ is the data treatment error.

$348 \quad$ Equation 8

$$
D_{T h}=\sqrt{D_{A n}^{2}+E_{M e a s}^{2}+E_{T r}^{2}}-\frac{a}{N-1}
$$

\section{Equation 9}

$$
D_{T h}=\sqrt{D_{A n}^{2}+\frac{E_{M e a s}^{2}+E_{T r}^{2}}{2}}-\frac{a}{N-1}
$$

The theoretical uncertainties follow a simple error propagation equation, which is

351 expressed as shown in equation 10 for single points measurements, and equation 11 for 352 orthogonal couples. Here, $E_{\text {Cor }}$ plays a role on the final relative error and tends to account for 353 most of the uncertainty when the number of points increases (see Figure 5).

\section{Equation 10}

$$
E_{T h}=\sqrt{\frac{D_{A n}^{2}+E_{M e a s}^{2}+E_{T r}^{2}}{N}+E_{C o r}^{2}}
$$

\section{Equation 11}

$$
E_{T h}=\sqrt{\frac{D_{A n}^{2}+\frac{E_{M e a s}^{2}+E_{T r}^{2}}{2}}{N}+E_{C o r}^{2}}
$$


This is the peer-reviewed, final accepted version for American Mineralogist, published by the Mineralogical Society of America. The published version is subject to change. Cite as Authors (Year) Title. American Mineralogist, in press.

DOI: https://doi.org/10.2138/am-2021-7264. http://www.minsocam.org/

Each of the above equations can be applied for both olivine and wadsleyite. All the parameters are displayed in Table 1.

It can be noted that all the dispersions and errors in this simulation neglect the initial asymmetry of the distribution of the $\mathrm{OH} / \mathrm{Si}$ values (see distribution histograms in supplementary

361 single points measurements and low values for the orthogonal couples), rapidly tends toward a

362 Gaussian-shaped distribution above 10 to 15 points. Moreover, the asymmetry of the distribution

363 might be very difficult to observe on a real set of measurement because of the limited set of

364 points in which the distribution of values may not have any statistical significance. Hence, the

365 deviation caused by this hypothesis tends to be negligible above 10 to 15 measurement points,

366 but very low number of points should still follow a very asymmetric distribution, increasing 367 error.

It can be noted that the measurement and treatment errors have a very small effect on both

369 the dispersion and the error (see Figure 5). On the other hand, power drift correction related

370 errors $\left(\mathrm{E}_{\mathrm{Cor}}\right)$ have a very strong effect on the final error, demonstrating that this step must be

371 carefully performed in order to get correct values. An important result is that the use of averaged

372 orthogonally polarized measurements roughly halves the theoretical dispersion of the values, thus

373 decreasing the associated error. The total expected dispersion directly related to anisotropy

374 (neglecting all the other error sources) for olivine is around $\pm 29.4 \%$ for single points and $\pm 14.8 \%$

375 for orthogonal couples. Wadsleyite displays slightly higher values, with $32.5 \%$ and $16.8 \%$ (all

376 these values are shown in Table 1). The same effect could be reached on single points

377 measurements with approximately four times more points. Another advantage of using the 
378 orthogonal couples is that it forces to measure more diverse grain orientations in the sample,

379 hence limiting the effect of a potential preferential crystallographic orientation within the sample.

To sum up, assuming a chemically homogeneous sample (in terms of water content), if

381 the standard deviation is close to the expected dispersion (calculated with equations 8 or 9), the

382 real analytical error is given by equations 10 or 11 . It follows that, in the ideal case of randomly

383 oriented crystals, the error on $\mathrm{OH} / \mathrm{Si}$ for 5 to 10 measurement points is between 15 and $18 \%$ for

384 single points, and 12 and $15 \%$ for orthogonal couples. A deviation inferior to the expected

385 deviation (still assuming that the sample is homogeneous) would point out an insufficient

386 sampling of the natural dispersion. A rough estimation of the real error in this case can be

387 obtained with equation 12 . Here, the difference between the expected deviation $D_{T h}$ and the

388 measured value $D_{S m p}$ causes the final error $\left(E_{S m p}\right)$ to increase from the ideal value $E_{T h}$ to the total

389 dispersion $D_{T h}$, equal to the error expected on a measurement based on one single measurement

390 point.

391 In contrast, if the standard deviation is higher than $D_{T h}$, whether because the sample is

392 heterogeneous or the measurements are too defective, the error "reduction" from $D_{S m p}$ to $E_{S m p}$

393 (from equations 8 or 9 to equations 10 or 11) may not be reasonable to apply directly.

394 Considering that the sampling is sufficient in this case, an error approximation can be obtained

395 from equation 10 (variables are the same as in equation 13).

396 Equation 12

$$
E_{S m p}=D_{T h}-\left(D_{T h}-E_{T h}\right) \times \frac{D_{S m p}}{D_{T h}}
$$




$$
E_{S m p}=\sqrt{\left(D_{S m p} \times \frac{E_{T h}}{D_{T h}}\right)^{2}+\left(D_{S m p}-D_{T h}\right)^{2}}
$$

\section{Olivine and wadsleyite calibration lines}

The water content of the samples used to build the calibration lines are shown in Table 2,

400 along with the values of $\mathrm{OH} / \mathrm{Si}$ measured with Raman spectroscopy. The calibration lines (see

401 equation 14 and Figure 6) are built with least-square minimization, always pass by the origin, and

402 take into account the effect of the water content uncertainties arising from FTIR and ERDA

403 measurements as well as the Raman measurement. All the error bars on the $\mathrm{OH} / \mathrm{Si}$ have been

404 estimated with the method described above. Some samples thus display a relatively large error

405 bar (such as 949 or M380b, see Figure 6 and Table 2) because the measured dispersion was

406 significantly greater than the expected dispersion (obtained from equations 8 to 11). On the other

407 hand, some samples, such as M382, displayed a very low dispersion that may be related to

408 insufficient sampling, once again resulting in a larger error bar. The factor to convert from $\mathrm{OH} / \mathrm{Si}$

409 to $\mathrm{ppm}$ in weight of water ( $F$ in equation 11$)$ is $93108 \pm 24005$ for olivine, $250868 \pm 45591$ for

410 wadsleyite (with iron), and $57546 \pm 13916$ for wadsleyite (without iron). This result shows the

411 tremendous effect of iron on the spectrum's shape and intensity, implying that chemical

412 composition has to be verified in order to quantify the water content of wadsleyite. There are two

413 identified causes to this difference, the first being that for two samples with comparable water

414 contents, the Si area of an iron-free wadsleyite displays sharper peaks, even if their heights are

415 comparable, implying a lower $\mathrm{Si}$ intensity. However, at the same time, its $\mathrm{OH}$ area is more

416 intense. This causes the $\mathrm{OH} / \mathrm{Si}$ of an iron-free wadsleyite to be much higher than the one of an 
417 iron-bearing wadsleyite with a comparable water content (see supplementary materials 5). Figure

4186 displays the calibration lines for olivine and wadsleyite.

\section{$419 \quad$ Equation 14}

$$
\mathrm{C}_{\mathrm{H}_{2} \mathrm{O}}\left(\text { ppmwt) }=F \times \frac{\mathrm{OH}}{\mathrm{Si}}_{S m p \text { Norm }}\right.
$$

The uncertainty on the slope obtained for each calibration has to be added to the final

421 error $E_{S m p}$ described above, the total uncertainty on the water content being given by equation 15 ,

422 where $\mathrm{E}_{\mathrm{H} 2 \mathrm{O}}$ is the total error, $E_{S m p}$ is the total relative error on the $\mathrm{OH} / \mathrm{Si}$ of the sample, and $E_{C a l}$ is 423 the calibration-related relative error. The same can be applied to dispersions.

\section{Equation 15}

$$
E_{H_{2} O}=\sqrt{E_{S m p}^{2}+E_{C a l}^{2}}
$$

The uncertainty on the slope of the calibration line (as shown in Figure 6) arising from the

427 errors in water quantification of the standards and from the error on their $\mathrm{OH} / \mathrm{Si}$ often becomes

428 the major component of the total uncertainty on the water content compared to the error on the measurement of $\mathrm{OH} / \mathrm{Si}$ with Raman spectroscopy.

Regarding olivine, the $26 \%$ uncertainty on the calibration line is much larger than the $43112 \%$ error on the $\mathrm{OH} / \mathrm{Si}$ measurement attained for a large number of points (in the case of 432 orthogonal couples, see Figure 5). Following equation 15, this $12 \%$ error $\left(E_{S m p}\right)$ increases to $29 \%$

433 only because of the uncertainty on the calibration $\left(E_{C a l}\right)$. The same problem applies to wadsleyite 434 with the $18 \%$ error on the calibration line for iron-bearing wadsleyite and the $24 \%$ error for iron- 
This is the peer-reviewed, final accepted version for American Mineralogist, published by the Mineralogical Society of America. The published version is subject to change. Cite as Authors (Year) Title. American Mineralogist, in press.

DOI: https://doi.org/10.2138/am-2021-7264. http://www.minsocam.org/

435 free wadsleyite. The greater is the error on the $\mathrm{OH} / \mathrm{Si}$ of the sample (because of insufficient

436 sampling or sample heterogeneities), the smaller the contribution of calibration uncertainties to

437 the total error will be (see Figure 7).

438 DISCUSSION

The quantification of as much error and uncertainty sources as possible provides a better understanding of the data dispersion inherent to the use of Raman spectroscopy on anisotropic

441 crystals. The relative impact of each source of error highlights what affects the more the final

442 error, showing where further progress and developments could be made. The first issue is the

443 laser-drift during and between different sessions. The method used to overcome this problem

444 brings an additional source of error (referred as $\mathrm{E}_{\mathrm{Cor}}$ throughout this study), as it implies two

$445 \mathrm{OH} / \mathrm{Si}$ ratio measurements on a standard glass, thus adding twice data treatment and

446 measurement error to the result (divided by $\sqrt{ } 2$, as the value measured is supposed to be the same

447 for the two measurements). Moreover, as this correction has to be applied on all the points of a

448 sample, its contribution to the total error does not decrease with an increasing number of points.

449 Consequently, its relative contribution increases, and becomes the major part of the error on the

$450 \mathrm{OH} / \mathrm{Si}$ ratio above around 20 to 25 single points, or 5 orthogonal couples (see Figure 5). This

451 power-drift correction error is also responsible for a significant part of the calibration error, thus

452 acting in two different ways in the final error. On the other hand, insufficient sampling of the

453 natural dispersion rapidly causes the final error to be larger than the measured dispersion (see

454 equation 11). Orthogonally polarized averaged measurements, improving by force the sampling

455 of various orientations (and thus, anisotropy) help to prevent from orientation biases.

Secondly, the effect of the calibration uncertainty (caused by the errors on each standard

point) on the final error acts similarly as the power-drift correction uncertainty (both are 
insensitive to the number of points), rapidly becoming the major part of the error, particularly for

459 olivine. Focusing on the ideal case where the dispersion observed on the sample $\left(D_{S m p}\right)$ equals the

460 theoretical dispersion $\left(D_{T h}\right)$, implying that $E_{S m p}$ and $E_{T h}$ are equal, the conversion factors $D_{H 2 O} /$

$461 E_{H 2 O}$ (following equation 15 , and applying this to the dispersion by replacing $E_{S m p}$ with $D_{S m p}$ to

462 obtain $D_{H 2 O}$ ) and $D_{S m p} / E_{S m p}$ of wadsleyite are superior to those of olivine in all cases (except for

463 two points in the orthogonal couples case, see Figure 7). This is caused by the higher effect of the

464 error sources on $D_{T h}$ than on $E_{T h}$ in the case of wadsleyite, where $E_{C o r}$ mitigates their effect, hence

465 increasing $D_{S m p} / E_{S m p}$. Adding $E_{C a l}$ does not change this observation, except that it mitigates these

466 effects, lowering the expected "gain" on errors, with higher attenuation for higher $E_{C a l}$ (see Figure

467 7). In the case of a poor sampling, accounting for $E_{C a l}$ tends to mitigate the effect of the error

468 augmentation (see equation 9) by increasing $E_{S m p}$ to a much higher $E_{H 2 O}$, lowering the effect of 469 equation 15.

Water content heterogeneities may cause the measured dispersion to be larger than the

471 expected one. In such cases, when the ratio of observed over expected dispersion is close to one,

472 even if the gain may seem high, it is important to consider that chemical heterogeneities should

473 remain as low as possible (see the discussion around equation 13). The present water

474 quantification method by Raman spectroscopy relies on the hypothesis that only the orientation

475 varies from one crystal to another, and that these orientations are distributed randomly and

476 uniformly. This means that chemically heterogeneous samples (should it be a major element

477 content variation, or in water content variation) are unsuitable for precise water quantification

478 with this method. In the case of wadsleyite, we observed that the iron content has a tremendous

479 effect on the calibration line slope, implying that composition has to be measured to verify if all

480 the analyzed crystals have a similar iron content. The problem of the random distribution of 
481 orientations in samples also has to be considered, as preferential orientation may occur in some

482 samples. However, if a sample is chemically homogeneous, a sample with a strong disparity of

483 orientations could be identified if it displays values dispersion much smaller than the expected

484 dispersion (see discussion around equation 12).

\section{CONCLUSION}

Raman spectroscopy allows the water content measurement of samples of any size above

487 few micrometers, and with water contents down to 150-200 ppm in weight (see Bolfan-Casanova

488 et al. 2014), with no observed upper limit, where many other methods may require large samples,

489 or are unsuitable for very high water contents (FTIR). Even if vibrational spectroscopy is very

490 useful to discriminate $\mathrm{OH}$ point defects over contamination, the sensitivity to crystallographic

491 orientation in anisotropic samples often leads to high standard deviations in the measurements of

492 water content (Férot and Bolfan-Casanova 2012). Here we show that a large part of this

493 dispersion may be related to the natural anisotropy of the measured mineral, and is thus normal.

494 The main objective of this work was to be able to calculate the error associated to the

495 measurement of water content in olivine and wadsleyite, using Raman spectroscopy, knowing the

496 anisotropy of the $\mathrm{OH} / \mathrm{Si}$ ratio for each phase. We identified throughout this study various sources

497 of error. The major parameters (beside anisotropy) affecting errors on the final values are the

498 uncertainties on the calibration line, insufficient sampling of anisotropy, and the laser-drift

499 correction errors. Nevertheless, most of the errors obtained with this procedure fall in a range of

$50020-25 \%$ of relative error for wadsleyite, and $25-30 \%$ for olivine, making Raman spectroscopy

501 still suitable for quantification water content in olivine and wadsleyite. The detailed study of the

502 error sources has provided a greater understanding of the method, and has allowed an 
503 improvement of the treatment methods, reducing significantly the uncertainties arising from this

504 part of the procedure.

\section{IMPLICATIONS}

The high spatial resolution of Raman spectroscopy allows the study of water distribution among different phases of fine polymineralic samples of complex (natural) composition, with a

508 wide range of measurable water contents. Although relatively high, the uncertainties on water

509 concentration are sufficiently low to infer the effect of thermodynamic intensive parameters on

510 water incorporation. The method proposed here can also be applied to all orthorhombic minerals.

\section{ACKNOWLEDGMENTS}

512 The authors thank Jean-Louis Fruquière and Cyrille Guillot for their help and advises on

513 the experimental assemblies, István Kovács, Anthony Withers, and Mainak Mookherjee for very 514 precise and helpful reviews of this manuscript, Federica Schiavi and Arnaud Guillin for fruitful

515 discussions, and Laurent Jouffret for the time spent on the orientation attempt of the wadsleyite

516 single crystal with X-ray diffraction. The multi-anvil apparatus of Laboratoire Magmas et 517 Volcans is financially supported by the CNRS (Instrument national de 1'INSU). This is 518 Laboratory of Excellence ClerVolc contribution $\mathrm{N}^{\circ} 419$.

\section{REFERENCES}

520 Ardia, P., Hirschmann, M.M., Withers, A.C., and Tenner, T.J. (2012) H2O storage capacity of

521 olivine at 5-8 GPa and consequences for dehydration partial melting of the upper mantle.

522 Earth and Planetary Science Letters, 345-348, 104-116. 
523 Asimow, P.D., Stein, L.C., Mosenfelder, J.L., and Rossman, G.R. (2006) Quantitative polarized infrared analysis of trace $\mathrm{OH}$ in populations of randomly oriented mineral grains. American Mineralogist, 91, 278-284.

Bali, E., Bolfan-Casanova, N., and Koga, K.T. (2008) Pressure and temperature dependence of H solubility in forsterite: An implication to water activity in the Earth interior. Earth and Planetary Science Letters, 268, 354-363.

Bell, D.R., and Rossman, G.R. (1992) Water in Earth's mantle: The role of nominally anhydrous minerals. Science, 255, 1391-1397.

531 Bell, D.R., Rossman, G.R., Maldener, J., Endisch, D., and Rauch, F. (2003) Hydroxide in olivine: A quantitative determination of the absolute amount and calibration of the IR spectrum. Journal of Geophysical Research, 108, 2105. olivine using Raman spectroscopy. American Mineralogist 99, 149-156.

536 Bolfan-Casanova N., Schiavi, F., Novella, D., Bureau, H., Raepsaet, C., Khodja, H., and Demouchy S. (2018) Examination of Water Quantification and Incorporation in lithospheric mantle: A review. Lithos, 240-243, 402-425. 
542 Férot, A., and Bolfan-Casanova, N. (2012) Water storage capacity in olivine and pyroxene to 14 GPa: Implications for thewater content of the Earth's upper mantle and nature of seismic discontinuities. Earth and Planetary Science Letters, 349-350, 218-230.

545 Fischer, G.W., and Medaris, L.G. (1969) Cell dimensions and X-ray determinative curve for synthetic Mg-Fe olivines. American Mineralogist, 54, 741-753.

Inoue, T., Yurimoto, H., and Kudoh, Y. (1995) Hydrous modified spinel, Mg1.75SiH0.5O4: A new water reservoir in the mantle transition region. Geophysical Resaerch Letters, 22, issue 2, 117-120.

Ishibashi, H., Arakawa, M., Ohi, S., Yamamoto, J., Miyake, A., and Kagi, H. (2008) Relationship between Raman spectral pattern and crystallographic orientation of a rock-forming mineral: a case study of Fo89Fa11 olivine. Journal of Raman Spectroscopy, 39, 16531659.

Jacobsen, S.D, Demouchy, S., Frost, D.J., Boffa Ballaran, T., and King, J. (2005) A systematic study of $\mathrm{OH}$ in hydrous wadsleyite from polarized FTIR spectroscopy and single-crystal X-ray diffraction: Oxygen sites for hydrogen storage in Earth's interior. American Mineralogist, 90, 61-70. using SIMS and FTIR: Comparison and calibration for nominally anhydrous minerals. Geochemistry Geophysics Geosystems, 4, number 2, 1019.

561 Kohlstedt, D.L., Keppler, H., and Rubie, D.C. (1996) Solubility of water in the $\alpha, \beta$ and $\gamma$ phases of (Mg,Fe)2SiO4. Contributions to Mineralogy and Petrology, 123, 345-357. 
563

Kovács, I., Hermann, J., O'Neill, H.S.C., Fitz Gerald, J., Sambridge, M., and Horváth, G. (2008) Quantitative absorbance spectroscopy with unpolarized light: Part II. Experimental evaluation and development of a protocol for quantitative analysis of mineral IR spectra. American Mineralogist, 93, 765-778.

Kovács, I., O'Neill, H.S.C., Hermann, J. and Hauri, E.H. (2010) Site-specific infrared O-H absorption coefficients for water substitution into olivine. American Mineralogist 95, 292299.

Libowitzky, E., and Rossman, G.R. (1996) Principles of quantitative absorbance measurements in anisotropic crystals. Physics and Chemistry of Minerals, 23, 319-327.

Litasov, K.D., Shatskiy, A., and Ohtani, E. (2014) Melting and subsolidus phase relations in peridotite and eclogite systems with reduced $\mathrm{C}-\mathrm{O}-\mathrm{H}$ fluid at 3-16GPa. Earth and Planetary Science Letters, 391, 87-99.

Mercier, M., Di Muro, A., Giordano, D., Métrich, N., Lesne, P., Pichavant, M., Scaillet, B., Clocchiatti, R., Montagnac, G. (2009) Influence of glass polymerisation and oxidation on micro-Raman water analysis in alumino-silicate glasses. Geochimica et Cosmochimica Acta, 73, 197-217.

Mosenfelder, J.L., Le Voyer, M., Rossman, G.R., Guan, Y., Bell, D.R., Asimow, P.D., and Eiler, J.M. (2011) Analysis of hydrogen in olivine by SIMS: Evaluation of standards and protocol. American Mineralogist, 96, 1725-1741.

Novella, D., Frost, D.J., Hauri, E.H., Bureau, H., Raepsaet, C., and Roberge, M. (2014) The distribution of $\mathrm{H} 2 \mathrm{O}$ between silicate melt and nominally anhydrous peridotite and the 
onset of hydrous melting in the deep upper mantle. Earth and Planetary Science Letters, $400,1-13$.

586

Peslier, A.H. (2010) A review of water contents of nominally anhydrous natural minerals in the mantles of Earth, Mars and the Moon. Journal of Volcanology and Geothermal Research, $197,239-258$.

Qiu, Y., Jiang, H., Kovács, I., Xia, Q.K. and Yang, X. (2018) Quantitative analysis of H-species in anisotropic minerals by unpolarized infrared spectroscopy: An experimental evaluation. American Mineralogist, 103, 1761-1769.

Schiavi, F., Bolfan-Casanova, N., Withers, A.C., Médard, E., Laumonier, M., Laporte, D., Flaherty, T., and Gómez-Ulla, A. (2018) Water quantification in silicate glasses by Raman spectroscopy: Correcting for the effects of confocality, density and ferric iron. Chemical Geology, 483, 312-331.

Smyth, J.S., and Keppler, H., Eds. (2006) Water in nominally anhydrous minerals. Reviews in Mineralogy and Geochemistry, 62.

Tenner, T.J., Hirschmann, M.M., Withers, A.C., and Ardia, P. (2012) H2O storage capacity of olivine and low-Ca pyroxene from 10 to $13 \mathrm{GPa}$ : consequences for dehydration melting above the transition zone. Contributions to Mineral Petrology, 163, 297-316.

Thomas, S.M., Thomas, R., Davidson, P., Reichart, P., Koch-Müller, M., and Dollinger, G. (2008) Application of Raman spectroscopy to quantify trace water concentrations in glasses and garnets. American Mineralogist, 93, 1550-1557. 
604 Thomas, S.M., Jacobsen, S.D., Bina, C.R., Reichart, P., Moser, M., Hauri, E.H., Koch-Müller, M., Smyth, J.R., and Dollinger, G. (2015) Quantification of water in hydrous ringwoodite. Frontiers in Earth Sciences, 2, 38.

607 Thomas, S.M., Wilson, K., Koch-Müller, M., Hauri, E.H., McCammon, C., Jacobsen, S.D., majoritic garnet. American Mineralogist, 100, 1084-1092.

610 Weis, F.A., Lazor, P., and Skogby, H. (2018) Hydrogen analysis in nominally anhydrous minerals by transmission Raman spectroscopy. Physics and Chemistry of Minerals, 45,

613 Withers, A.C., and Hirschmann, M.M. (2007) H2O storage capacity of MgSiO3 clinoenstatite at 8-13 GPa, $1100-1400^{\circ} \mathrm{C}$. Contributions to Mineralogy and Petrology, 154, 663-674.

615 Withers, A.C., and Hirschmann, M.M. (2008) Influence of temperature, composition, silica activity and oxygen fugacity on the $\mathrm{H} 2 \mathrm{O}$ storage capacity of olivine at $8 \mathrm{GPa}$. Contributions to Mineralogy and Petrology, 156, 595-605.

618 Withers, A.C., Bureau, H., Raepsaet, C., and Hirschmann, M.M. (2012) Calibration of infrared spectroscopy by elastic recoil detection analysis of $\mathrm{H}$ in synthetic olivine. Chemical Geology, 334, 92-98.

621 Withers, A.C. (2013) On the use of unpolarized infrared spectroscopy for quantitative analysis of absorbing species in birefringent crystals. American Mineralogist, 98,689-697 
623 Yang, X. (2016) Effect of oxygen fugacity on $\mathrm{OH}$ dissolution in olivine under peridotitesaturated conditions: An experimental study at 1.5-7 GPa and $1100-1300^{\circ} \mathrm{C}$. Geochimica et Cosmochimica Acta, 173, 319-336.

626 Yoshino, T., Nishihara, Y., Karato, S. ichiro (2007) Complete wetting of olivine grain boundaries by a hydrous melt near the mantle transition zone. Earth and Planetary Science Letters, $256,466-472$

629 Zarei, A., Klumbach, S., and Keppler, H. (2016) The relative Raman scattering cross sections of $630 \mathrm{H}_{2} \mathrm{O}$ and $\mathrm{D}_{2} \mathrm{O}$, with implications for in situ studies of isotope fractionation. ACS Earth and Space Chemistry, 2, 925-934. 
633 Table 1: Fitting parameters $\left(D_{A n}\right.$ and $\left.a\right)$ and estimated error sources values $(E)$ for

634 dispersion and error equations (equations 6 to 13). $D_{A n}$ is the calculated anisotropy contribution to

635 the observed values deviation; $E_{\text {Meas }}$ is the measurement related error, $E_{T r}$ the treatment related

636 error, and $E_{C o r}$ the laser-drift correction related error.

\section{Olivine}

$D_{A n}$

a

$E_{\text {Meas }}$

$E_{T r}$

$E_{\text {Cor }}$
Single points

28.1

6

4.44

3.58

11.9
Orthogonal couples

14.1

3

4.44

3.58

11.9
Wadsleyite Single points Orthogonal couples

32.5

6.74

4.25

3.82

11.9
16.8

3.37

4.25

3.82

11.9 
639 concentration in $\mathrm{ppm}$ by weight of water. Wadsleyite* standards are iron-free. Raman

640 measurement type "1" refers to the case of single point measurement and "2" to the case of

641 orthogonal couples.

\begin{tabular}{cl|ccc|cccc} 
& & \multicolumn{3}{|c|}{ Source measurement } & \multicolumn{4}{c}{ Raman measurement } \\
Sample & Phase & Method & ppm wt $\mathbf{H}_{\mathbf{2}} \mathbf{O}$ & error & Type & Points & OH/Si & error \\
\hline $\mathbf{9 4 9}$ & Olivine & FTIR & 1304 & 290 & 1 & 8 & 0.01534 & 0.00371 \\
M497 & Olivine & ERDA & 750 & 38 & 1 & 10 & 0.00405 & 0.00081 \\
M589 & Olivine & FTIR & 1244 & 596 & 1 & 57 & 0.01127 & 0.00141 \\
$\mathbf{1 0 3 3}$ & Olivine & FTIR & 522 & 176 & 2 & 11 & 0.00806 & 0.00118 \\
$\mathbf{8 9 5 b}$ & Olivine & FTIR & 180 & 21 & 2 & 12 & 0.00382 & 0.00156 \\
$\mathbf{1 0 4 4 b}$ & Olivine & FTIR & 1766 & 674 & 2 & 10 & 0.01924 & 0.00250 \\
M817 & Olivine & FTIR & 640 & 215 & 2 & 10 & 0.00350 & 0.00103 \\
M818 & Olivine & FTIR & 291 & 72 & 2 & 10 & 0.00269 & 0.00104 \\
\hline M230 & Wadsleyite & ERDA & 1045 & 52 & 1 & 10 & 0.01591 & 0.00270 \\
M226A & Wadsleyite & ERDA & 4209 & 210 & 2 & 12 & 0.03863 & 0.00642 \\
M380b & Wadsleyite & ERDA & 12206 & 610 & 1 & 10 & 0.04219 & 0.01833 \\
M382 & Wadsleyite & ERDA & 27271 & 1364 & 2 & 13 & 0.10122 & 0.01864 \\
\hline M226B & Wadsleyite & ERDA & 4000 & 200 & 2 & 10 & 0.10574 & 0.01457 \\
2053 & Wadsleyite $^{*}$ & ERDA & 21600 & 1080 & 1 & 10 & 0.46945 & 0.10382 \\
$\mathbf{2 0 5 4}$ & Wadsleyite $^{*}$ & ERDA & 34000 & 1700 & 1 & 10 & 0.49357 & 0.07957
\end{tabular}




\section{FigURE CAPTIONS}

Figure 1: Optical image of the olivine and wadsleyite samples used for the anisotropy

645 quantification.

Figure 2: Raman spectra of olivine (grey) and wadsleyite (black) in the silicate region

648 and the $\mathrm{OH}$ region. The wide bars underneath each graph (light bar for olivine, dark bar for

649 wadsleyite) depict the integration window used for water quantification. The darker short lines

650 depict the anchor point area used for baseline correction. The baseline shape is linear for olivine

$651 \mathrm{Si}$ area, and cubic for $\mathrm{OH}$ area, and is polylinear for wadsleyite $\mathrm{Si}$ area, and cubic for $\mathrm{OH}$ area.

Figure $3: \mathrm{OH} / \mathrm{Si}$ values of olivine (top) and wadsleyite (bottom) as a function of the

654 orientation of the crystal relative to the beam, for three perpendicular faces. Error bars are the

655 estimated uncertainties linked to measurement errors and data treatment (see text). Horizontal

656 error bars are an estimation of the angle's error. Solid and dashed lines (M) represent the fitted

657 curves obtained through equation 3 (or 4 for wadsleyite). Olivine crystallographic faces were

658 identified, whereas for wadsleyite, faces are named arbitrarily (F1, F2 and F3).

Figure 4 : Three-dimensional plot of $\mathrm{OH} / \mathrm{Si}$ values of olivine (as fitted in Figure 3 ) as a

661 function of crystallographic orientation. Values obtained with incident beam parallel to the $a$ axis

662 are displayed in the (100) (bc) plane, and so on for the other faces. Grey points (which due to 
663 their density may be displayed as light grey lines here) are the extrapolations of the solid lines

664 (derived from Figure 3) for any given orientation (see equation 5).

667 olivine (top) and wadsleyite (bottom), for the case of single point measurements (left) and 668 orthogonal couples (right), expressed in percent deviation from the average. Light grey symbols 669 stand for the contribution of anisotropy (An) alone. Adding the measurement (Meas) uncertainties 670 yields the intermediate grey symbols (mostly hidden by the dark grey ones). Adding treatment

671 (Tr) uncertainties gives the dark grey symbols, and finally adding the uncertainty arising from the 672 power correction (Cor) yields the black circles. show the $1 \sigma$ and $2 \sigma$ uncertainties respectively.

681 Full circles represent the ideal case where $D_{S m p}=D_{T h}$ (ideal sampling), thin circles represent the 682 insufficient sampling case (here, $D_{S m p}$ is $75 \%$ of $D_{T h}$ ), and thick circles represent the case of a 683 dispersion $D_{\text {Smp }} 50 \%$ superior to $D_{T h}$. 
Figure 1

\section{Olivine}

Wadsleyite

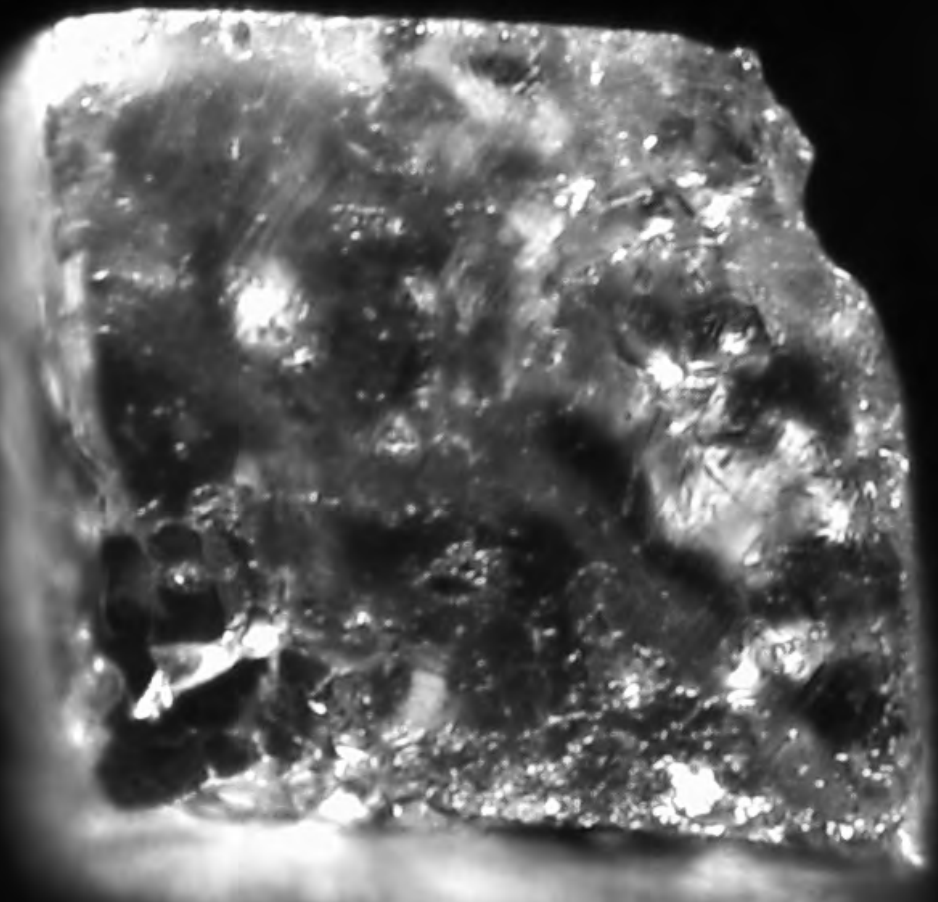

0
0
$\frac{3}{3}$

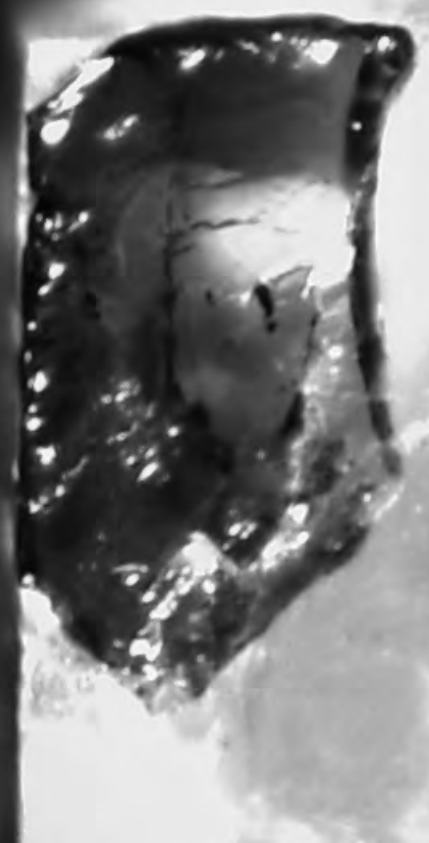


Figure 2
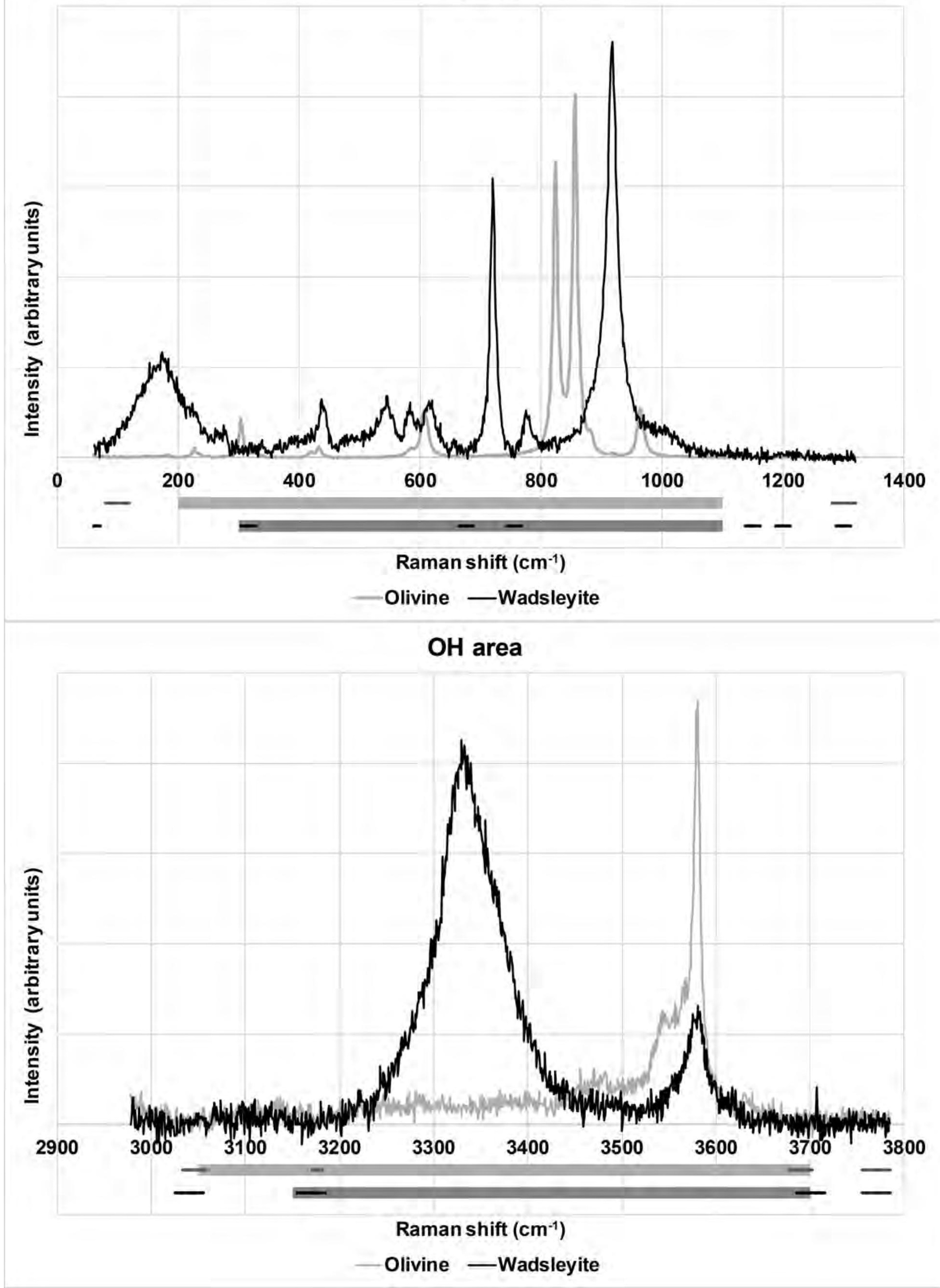
Figure 3

\section{Olivine $\mathrm{OH} / \mathrm{Si}$}
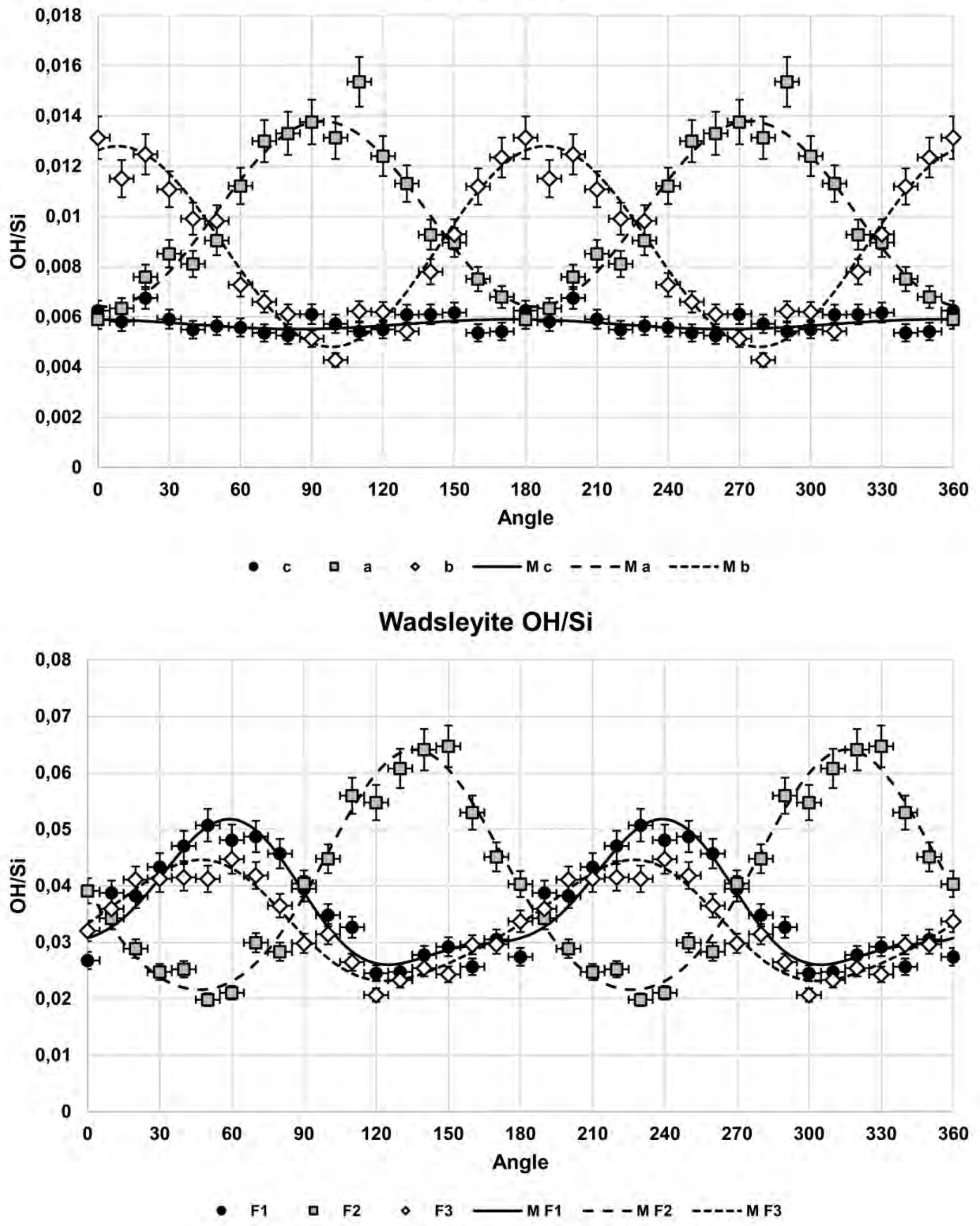
Figure 4

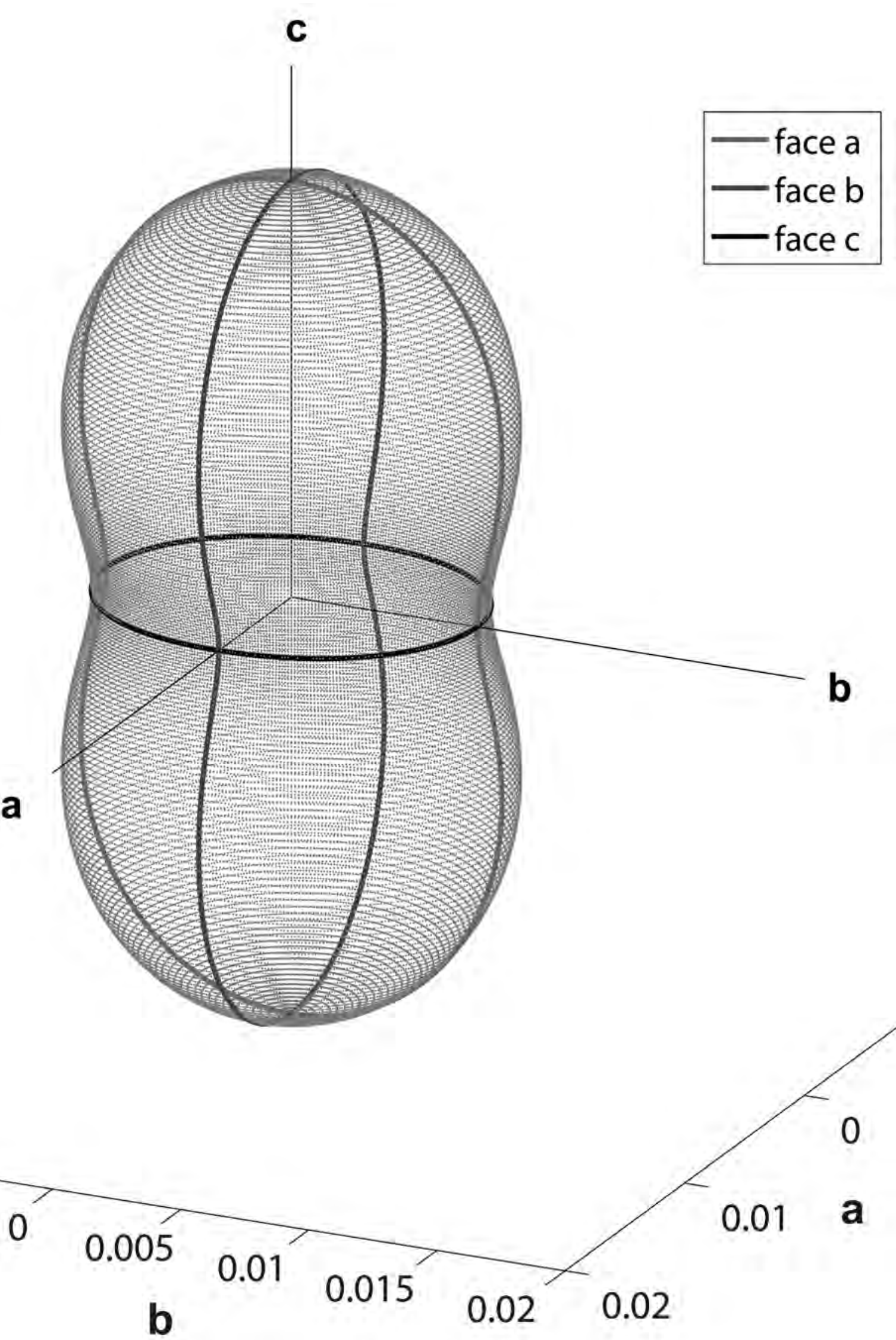


Figure 5 Olivine single points

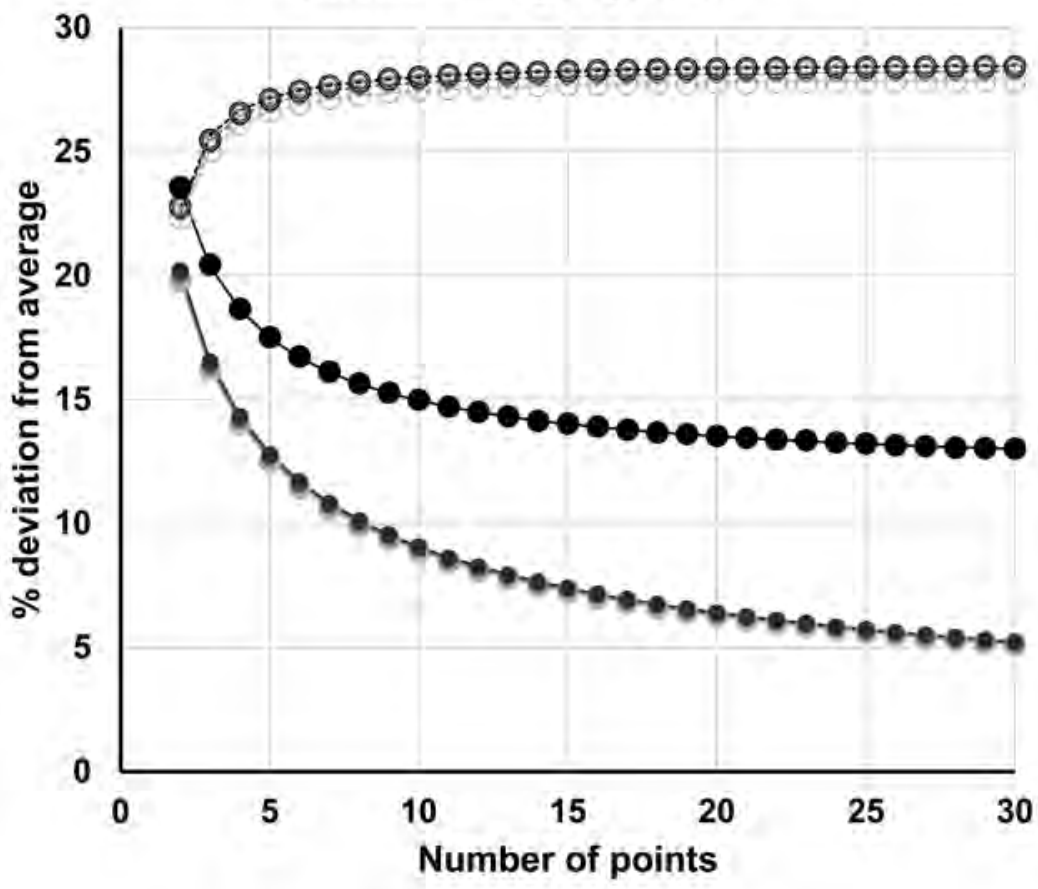

Wadsleyite single points

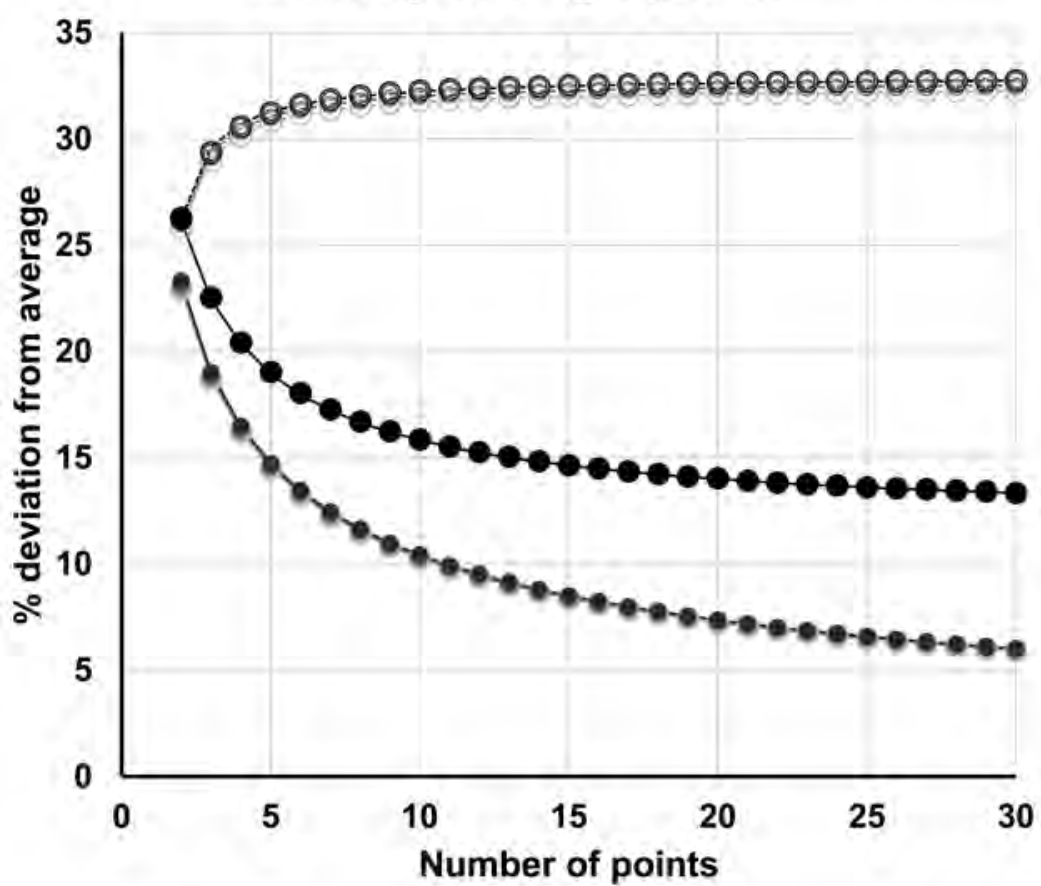

Disp An

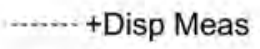

-....- +Disp $\mathrm{Tr}$

Disp An

o +Disp Meas

- +Disp Tr

...--.- +Disp Cor

o +Disp Cor

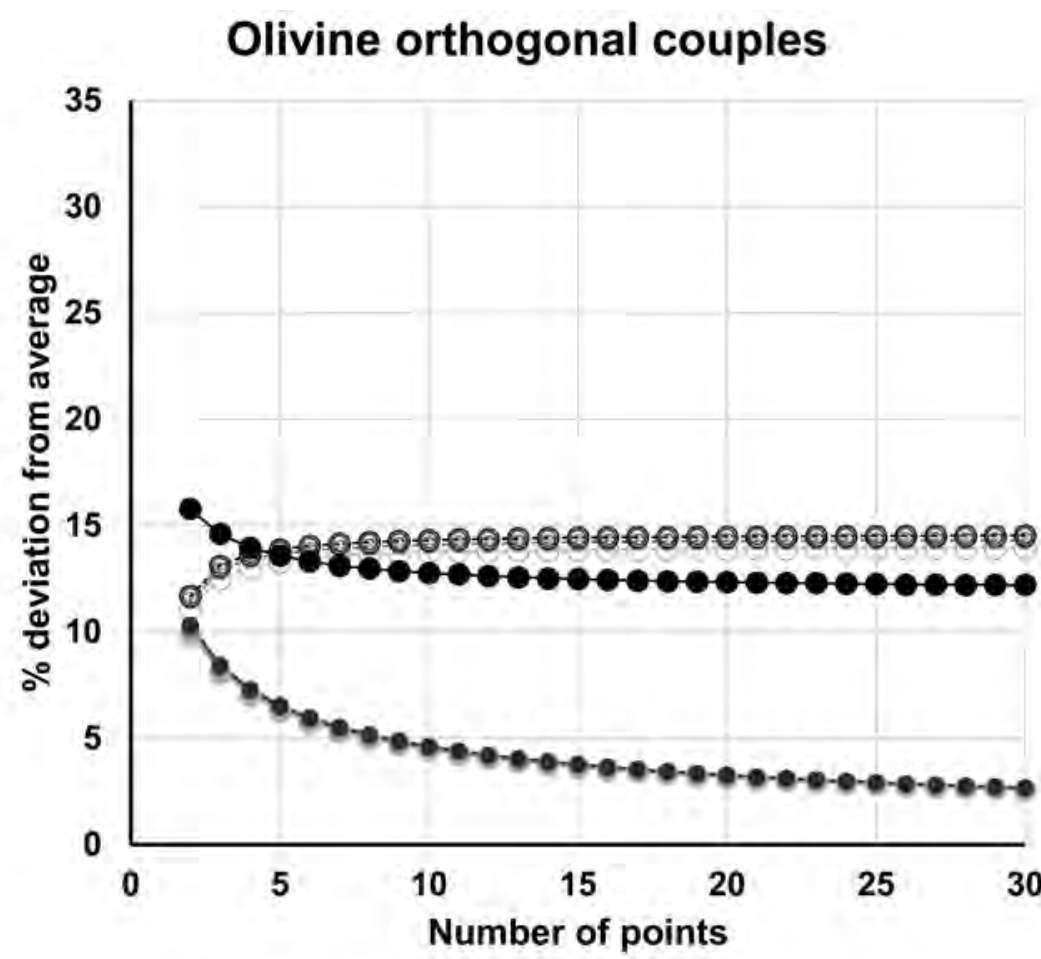

Wadsleyite orthogonal couples

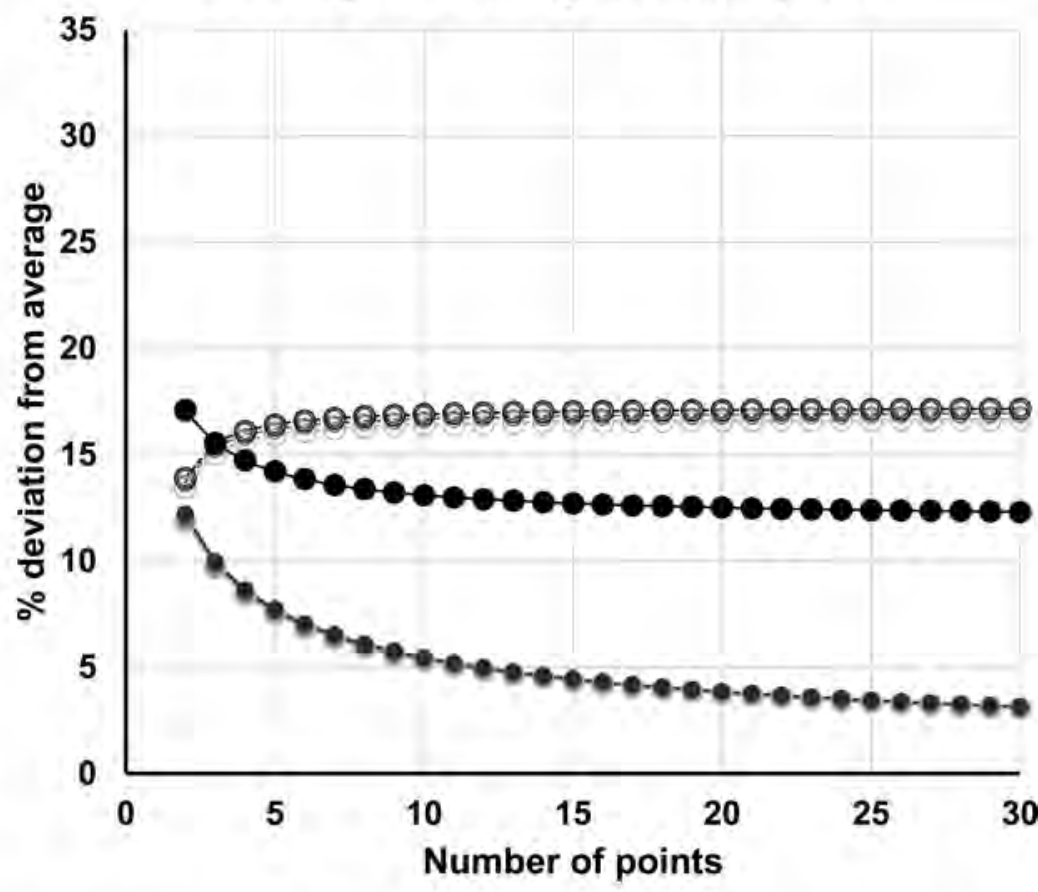

- Err An $\quad+$ Err Meas — + Err Tr $\quad+$ Err Cor

- ErrAn $\bullet+$ Errmeas $\bullet+$ Err Tr $\quad+$ Err Cor 

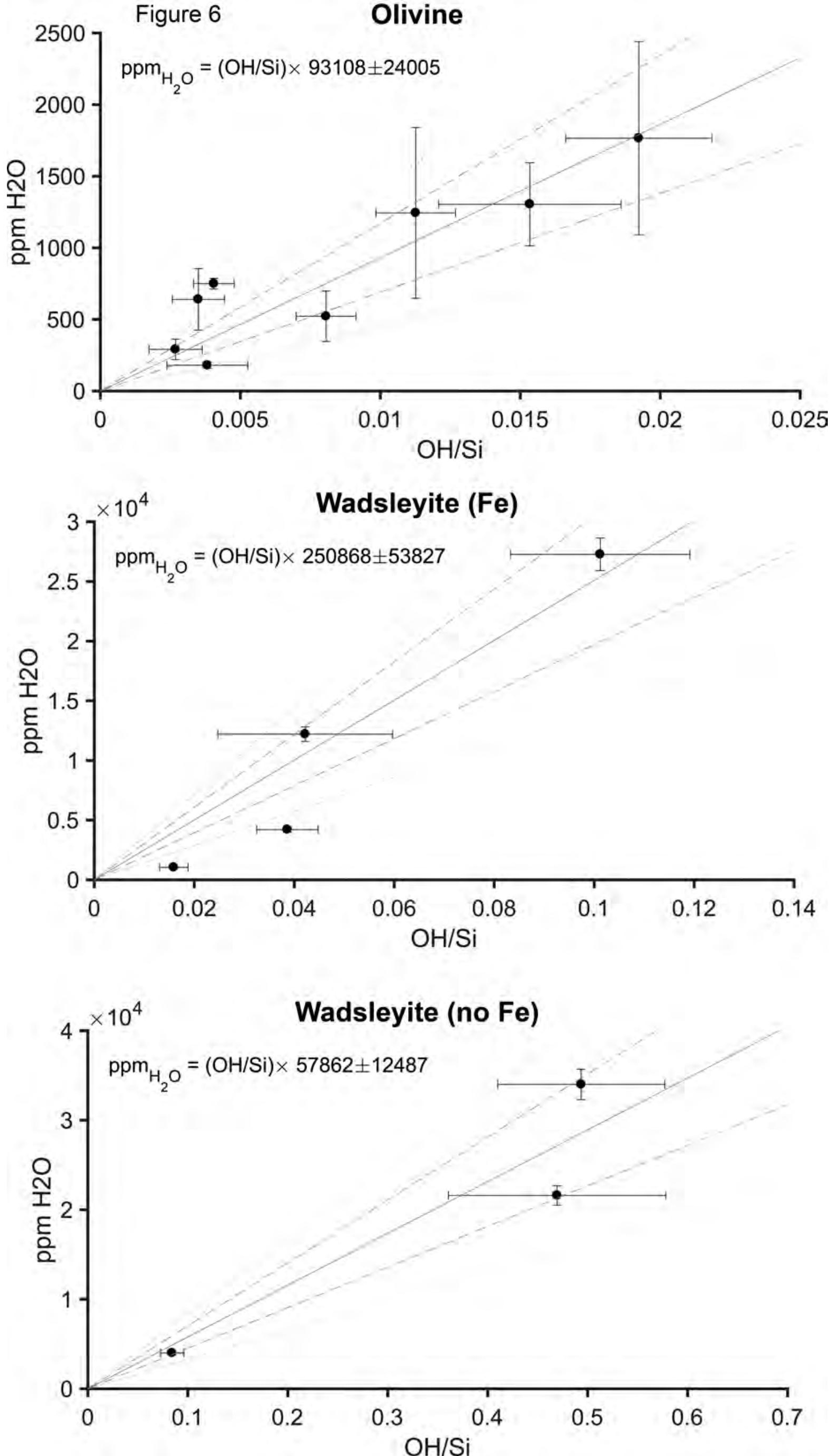

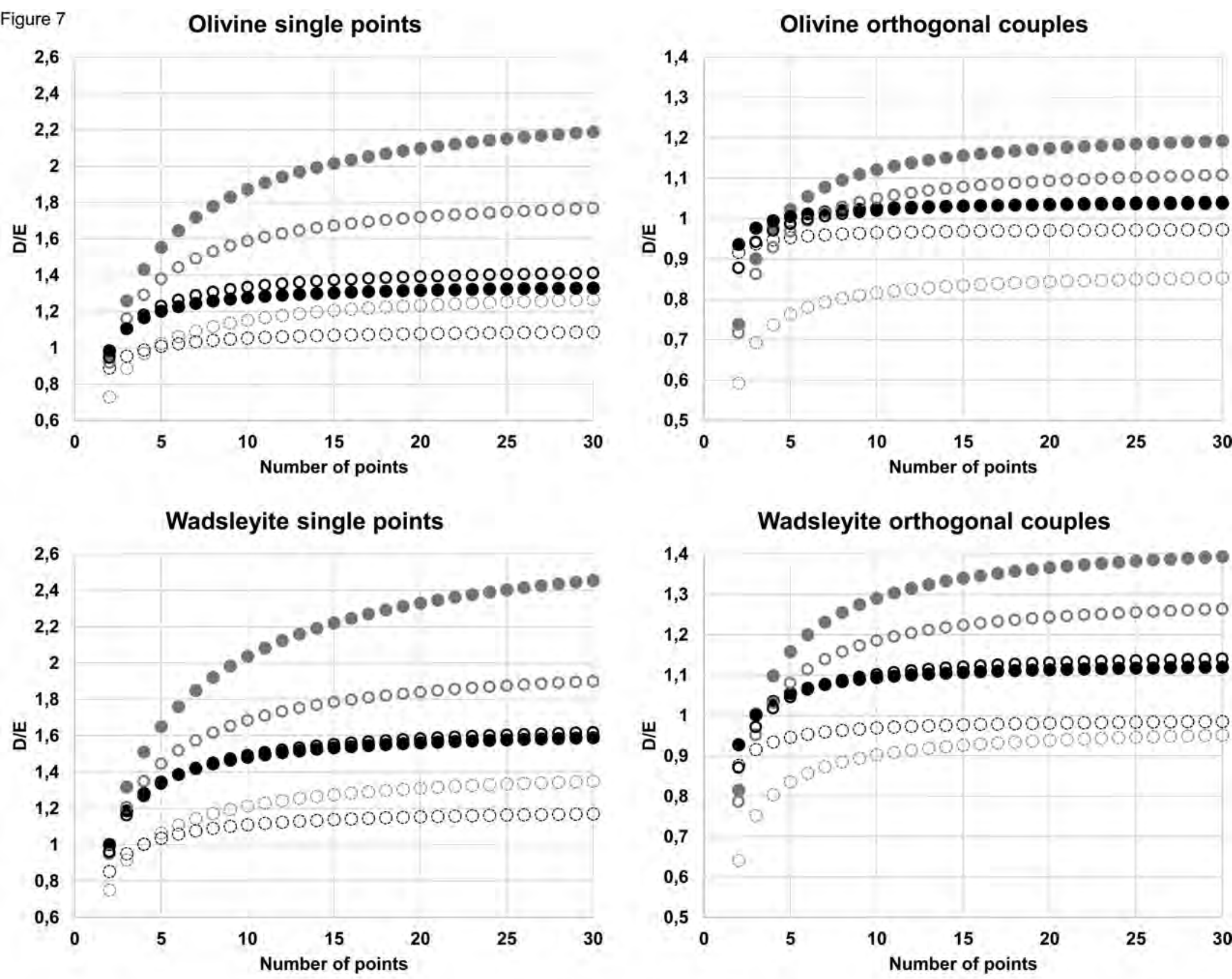

Smp $75 \% \quad \mathrm{H}_{2} \mathrm{O} 75 \% \quad$ O Smp $100 \%$

$\mathrm{O} \mathrm{H}_{2} \mathrm{O} 100 \%$

Smp $150 \%$

$\mathrm{H}_{2} \mathrm{O} 150 \%$ 